\title{
Disabled People's Organisations increase access to services and improve well-being: evidence from a cluster randomized trial in North India
}

Nathan John Grills ${ }^{1,2^{*}}$ (D, Monsurul Hoq ${ }^{3,4}$, Chun-Ping Pam Wong ${ }^{4}$, Komal Allagh ${ }^{5}$, Lawrence Singh ${ }^{6}$, Fairlene Soji ${ }^{7}$ and G. V. S. Murthy ${ }^{5}$

\begin{abstract}
Background: Disabled People's Organisations (DPOs) are the mainstay of disability responses worldwide. Yet there is no quantitative data assessing their effectiveness in low-and middle-income countries (LMICs). The aim of this study was to measure the effectiveness of DPOs as a low-cost intervention to improve well-being and access to services and facilities for people with disabilities.

Methods: We undertook a cluster randomised intervention control trial across 39 distinct rural villages in Uttarakhand State, North India. A total of 527 participants were included from 39 villages: 302 people from 20 villages were assigned to the intervention arm and 225 from 19 villages were assigned to the control group. Over a 2-year period, people with disabilities were facilitated to form DPOs with regular home visits. Participants were also given financial support for public events and exposure visits to other DPOs. Seven domains were used to measure access and participation.
\end{abstract}

Results: DPO formation had improved participation in community consultations (OR 2.57, 95\% Cl 1.4 to 4.72), social activities (OR 2.46, 95\% Cl 1.38 to 4.38), DPOs (OR 14.78, 95\% Cl 1.43 to 152.43), access to toilet facilities (OR 3.89, $95 \% \mathrm{Cl} 1.31$ to 11.57 ), rehabilitation (OR 6.83, 95\% Cl 2.4 to 19.42) and Government social welfare services (OR 4.82, $95 \% \mathrm{Cl} 2.35$ to 9.91 ) in intervention when compared to the control. People who were part of a DPO had an improvement in having their opinion heard (OR $1.94,95 \% \mathrm{Cl} 1.16$ to 3.24) and being able to make friends (OR 1.63, 95\% Cl 1 to 2.65) compared to those who were not part of a DPO. All other well-being variables had little evidence despite greater improvement in the DPO intervention group.

Conclusions: This is the first randomised control trial to demonstrate that DPOs in LMICs are effective at improving participation, access and well-being. This study supports the ongoing role of DPOs in activities related to disability inclusion and disability services. This study also suggests that supporting the establishment, facilitation and strengthening of DPOs is a cost-effective intervention and role that non-governmental organisations (NGOs) can play.

Trial registration: ISRCTN36867362, 9th Oct 2019 (retrospectively registered).

Keywords: Disability, Inclusion, India, Disabled People's Organisation, Access, Participation, Wellbeing, Rapid assessment of disability

\footnotetext{
*Correspondence: ngrills@unimelb.edu.au

${ }^{1}$ Nossal Institute for Global Health and Australia-India Institute, University of

Melbourne, Level 5, 333 Exhibition Street, Melbourne 3000, Australia

${ }^{2}$ Australia India Institute, University of Melbourne, 147-149 Barry Street,

Carlton, VIC 3053, Australia

Full list of author information is available at the end of the article
}

(c) The Author(s). 2020 Open Access This article is distributed under the terms of the Creative Commons Attribution 4.0 International License (http://creativecommons.org/licenses/by/4.0/), which permits unrestricted use, distribution, and reproduction in any medium, provided you give appropriate credit to the original author(s) and the source, provide a link to the Creative Commons license, and indicate if changes were made. The Creative Commons Public Domain Dedication waiver (http://creativecommons.org/publicdomain/zero/1.0/) applies to the data made available in this article, unless otherwise stated. 


\section{Background}

Disability is a complex phenomenon that results from interaction between the person's impairment and socioenvironmental barriers that limit their participation in society $[1,2]$. Thus, disability is an umbrella term, covering impairments, activity limitations and participation restrictions [1]. Worldwide, disability prevalence estimates range from $5-25 \%$ of the world's population and approximately $80 \%$ of people with disability live in developing countries $[1,3]$. In India, the census recorded $2.21 \%$ of the population as having a disability or around 26.8 million persons. However, other estimates, using different measures, indicate the figure could be much higher in India [4].

Evidence suggests that people with disabilities are more likely to experience adverse socioeconomic outcomes such as less education, poorer health outcomes, lower education achievements, less employment and higher rates of poverty than persons without disabilities $[1,4,5]$. Additionally, people with disabilities face barriers accessing health and rehabilitation services [2]. In response, disability inclusive development (DID) programs seek to ensure all stages of the development process are inclusive of and accessible to people with disabilities [6]. It goes beyond medical interventions and requires that all persons be afforded equal access to education, health care services, work and employment, and other social activities such as religion and recreation $[5,6]$. Low cost and evidence-based interventions are required to promote DID and improve lives of people with disabilities by addressing the socio-environmental barriers.

The United Nations Convention on the Rights of Persons with Disabilities (UNCPRD) expects that people with disabilities should be involved in all elements of the response to disability [7]. 'Nothing about us without us' has become the catch phrase of the disability rights movement. Accordingly, in actioning disability inclusive development, people with disabilities should be centrally involved. A central element to involving people with disabilities has been through the formation of Disabled People's Organizations (DPOs) and Disabled People's Networks [8]. DPOs grew out of the Disability Rights Movement of the 1970s and have become increasingly mainstreamed in most disability inclusive development programs [9]. DPOs help ensure that development process at all levels are inclusive of the voices and needs of people with disabilities and that they are aware of their rights and participate on an equal basis as others in all aspects of society [6]. DPOs intend to promote participation and well-being through activities such as advocacy, service provision and social support.

The general characteristics of a DPO, although often contested, are that:
- they are established by people with disabilities

- at the board and membership levels, they are controlled by a majority of persons with disabilities (at least 51\%) [2, 10];

- they provide persons with disability with "a voice of their own, identifying needs, expressing views on priorities, evaluating services and advocating change and public awareness" [2].

Some studies suggest that organized and registered DPOs working at state or regional level can promote regional cooperation and provide a powerful voice to people with disabilities [11-13]. Whilst increased voice is in itself an important substantive outcome, there is surprisingly little quantitative evidence that DPOs improve well-being and access to facilities and services for people with disabilities in LMICs [8]. A literature review by Young et al found that whilst DPOs could promote well-being, community participation, and rights of people with disabilities [14], there was little published evidence for their impact. While there are some examples of Self-Help Groups (SHGs) tackling some of the barriers facing people with disabilities [15], the disability sector views DPOs as distinct from SHGs and the representation by people with disability is considered of constitutive and instrumental importance [16]. Therefore, it is possible that evidence from a SHG would not be accepted as evidence of impact of a DPO. Furthermore, donors and partners of DPOs would be less likely to accept evidence from SHGs as a rationale for supporting DPOs, or as evidence that DPOs are effective. In fact, there was also a lack of randomised trials examining the effectiveness of DPOs. This is despite the WHO and many aid programs advocating both DPOs and DPO interventions in DID $[9,11]$.

To be able to measure the impact of DPOs, an effective quantitative tool is required to measure well-being, community participation and access to services. The Nossal Institute for Global Health, with support from Department of Foreign Affairs and Trade (DFAT), Australia and the Centre for Eye Research Australia, has developed the Rapid Assessment of Disability (RAD) survey tool to support the design, implementation and evaluation of DID activities [17]. This sophisticated research tool enables assessment of the impact of an intervention such as DPO formation.

Given the lack of data supporting DPOs, and the availability of an appropriate measurement tool, the primary aim of this study was to measure the effectiveness of DPOs as a low-cost intervention to promote access and wellbeing. This involved applying the RAD tool before and after the DPO facilitation (intervention), in both the intervention and control groups in Telangana and Uttarakhand. In this paper, we present the study results from the Uttarakhand. 


\section{Methods}

A cluster randomized interventional trial was conducted in the Dehradun district of Uttarakhand state in North India to evaluate the impact of DPOs on inclusion, well-being and participation. This study adheres to CONSORT guidelines for reporting clinical trials. The baseline survey was conducted in December 2014 to assess well-being, community participation and access and barriers to services among persons with disabilities [18]. The intervention, partly informed by the baseline results, involved facilitating the formation of DPOs and was carried out between February 2015 and February 2017. The endline survey was conducted over March and April 2017, and involved repeating the same tool used in the baseline on the same participants. Two parallel qualitative research projects were also undertaken to better understand the impacts of DPO and these were published elsewhere [14].

\section{Sampling technique}

A total of 39 villages (or clusters) were purposively selected from 5 distinct areas located in New Tehri and Dehradun districts of Uttarakhand. The project lead in each area selected 5-15 distinct villages to which they had access. Using a lottery system, 20 villages were randomly allocated to the intervention arm and 19 villages to the control arm.

Using an adapted Key Informant (KI) methodology we aimed to identify all people with disabilities from these 39 villages [19]. We consulted a) Government health workers (Anganwadi workers, ASHAs, Village heads), b) School teachers, c) NGO and postal workers, d) Local doctors, e) NGO workers, and f) Religious leaders as the Key Informants who were trained in "what disability is". All those with disabilities identified were then invited to participate in the study.

\section{Sample size}

All $(n=527)$ people with disabilities in the 39 villages were invited and were surveyed as part of the baseline survey. With 250 samples in each group we could detect a $10 \%$ increase in met needs in access to community participation/services or well-being among persons with disability with a statistical power of $74 \%$ and confidence interval (CI) of $95 \%$.

\section{RAD study tool}

The RAD survey questionnaire was utilized to evaluate the impact of community led DPOs, by applying the tool before and after intervention, in both the intervention and control groups. The questionnaire was developed by the Nossal Institute for Global Health and the Centre for Eye Research Australia, funded by the Government's aid programme, to fill a substantial gap in measuring disability. It was developed to identify people at risk of disability in terms of activity limitations and to determine well-being and participation in the community for people with disabilities compared to those without disabilities, and to ascertain associated barriers to participation posed by contextual factors [10]. The questionnaire was developed using two conceptual frameworks: the UNCRPD and the International classification of Functioning, Disability and Health (ICF) [7, 17].

The RAD questionnaire is comprised of elements adapted from existing tools including the Washington Group question set [20] and the Kessler scale. It comprises an interviewer administered household questionnaire and an individual questionnaire. It collects data under five sections: 1) Demographics, 2) Self-Assessment of functioning, 3) Awareness of rights of people with disabilities, 4) Wellbeing and quality of life, and 5) Participation in the community. Section 2 (self-assessment of functioning) asks about activity limitations over the last six months in seven domains: vision, hearing, communication, mobility, gross and fine motor skills, cognition and appearance. It also includes six questions about psychological distress using an adapted Kessler scale. Response categories were "none", "some of the time", and "all of the time". The RAD tool has been piloted in various settings including in Fiji, the Philippines, and Bangladesh and more recently in India $[10,21-23]$. The tool was also used to estimate the prevalence of disability in the two regions, the results of which have already been published $[18,23]$.

\section{Data collection}

\section{Pre- intervention phase: baseline RAD survey (November,} 2014)

A baseline RAD survey was conducted amongst people with disabilities from all villages to assess their wellbeing, community participation and access to services. Informed consent to participate in this study was obtained from all participants. A brief statement in simple, easy to understand English was provided and read out to participants with low literacy. The information about the survey was communicated in ways appropriate for specific disabilities.

\section{Intervention phase: formation of disabled People's Organisations (Feb 2015 - Jan 2017)}

In the intervention clusters, local NGOs facilitated the DPO formation by regular home visits to individual families motivating them to be involved in the activities of the DPOs. A curriculum and training program were also developed. Five NGOs, each within one of the intervention sites, were selected to assist in the intervention study and provide support for DPO formation. To ensure all participants in the intervention received the same services or benefits of DPOs, we selected 
implementing NGOs from the same registered organisation. These NGOs have worked collaboratively for 10 years and have worked closely together on disability for 8 years. We provided the same pre-study training and pilot. Further, all NGOs in the study met regularly during the study.

The participants with disability were encouraged to conduct weekly disability group meetings to facilitate problem solving, advocacy and planning. Every month, half-day training sessions were conducted on the formation of DPO using a DPO manual developed by Community Health Global Network. A regular monthly visit was undertaken by our team to provide ongoing support and encouragement in running twice yearly public events such as the world disability day and a religious festival. As a part of the DPOs, people with disabilities were encouraged to visit the block and district office and make at least three visits to the disability commissioner. Cross exposure visits were also organized, where members of one DPO visited another DPO to organize regular meetings at least monthly and to start new livelihood initiatives in areas of agriculture and horticulture. The interventions were carried out over a two-year duration.

In the non-intervention clusters, no DPOs were facilitated but the ongoing disability work continued. The control group only received referrals for disabilities detected by RAD screening, but without additional assistance. They received the interventions at the end of this study.

\section{Post intervention phase- Endline survey (Feb 2017)}

The RAD was utilized as an endline survey to assess the impact of DPO intervention on the lives of people with disabilities. Participants in both arms who had been interviewed in the baseline were invited to participate in the endline survey.

\section{Statistical analysis}

The responses for questions related to well-being and access to services were recoded into two groups in line with previously published findings from India [18]. The responses of "All the time" and "Most of the time" were categorised as felt well (well-being section) or Met need (access section). The responses "Some of the time" and "Never" were categorised as Felt unwell (well-being section) or Unmet need (access section). Responses such as "don't know" or "have not needed" were excluded.

Basic demographic characteristics were summarized using appropriate bi-variate statistics by intervention and control group at baseline and endline separately. All summary statistics were weighted by sampling weights i.e. total sample/number of samples in the cluster. The improvement in outcomes in well-being and access to services due to interventions were examined by Generalised
Estimated Equations model. Given the uneven sample sizes of people with disabilities in different villages, we adjusted for the clustering effect in the model. In the first model we estimated the effect of the intervention adjusting for the baseline status while in the second model the implementing NGO was included to adjust for their impact via the intervention on the outcome.

Kobo was used for data collection in the endline and MS Excel was used for cleaning and data management. Stata version 14 was used for data analysis (StataCorp, Texas, USA).

\section{Results \\ RAD survey}

Figure 1 shows the number of participants at each stage of the intervention study. A total of 527 persons with disabilities participated in the baseline RAD survey. Out of these participants $44(8.3 \%)$ were lost to follow-up (Table 1) meaning 483 participants were included in the final analysis.

\section{Characteristics of study participants}

Of the 483 participants, 272 (56\%) people with disability were in the intervention group and 211 (44\%) in the control group (Table 2). The only significant difference between intervention and control group was in socio economic status (SES) (specially in the middle 40\%). The other characteristics were similar between the two groups.

\section{Well-being of people with disabilities}

Participants in the intervention group demonstrated an increase in the positive responses (met needs) between the baseline and endline survey across all well-being variables (Table 3).

Most of the well-being items in model 1 demonstrated relatively higher odds of met needs in the intervention group than in the control group (Table 4). The clusteradjusted odds ratios were all above 1 after controlling for baseline status. In the second model, in which implementing NGO was added as a covariate, 'opinion being considered' (OR 1.94, 95\% CI 1.16 to $3.24, p=0.01$ ) and 'being able to make new friends' (OR 1.63, 95\% CI 1 to $2.65, p=0.05$ ) displayed positive association between intervention and met needs. Both suggested the odds of met needs (able to make new friends and opinion were considered) in the intervention group were approximately twice that of the control group.

\section{Access to services}

In regard to the access and participation variables there were consistently more individuals in the intervention groups who reported their needs were met in the endline compared with baseline (Table 5). Again, the increases 


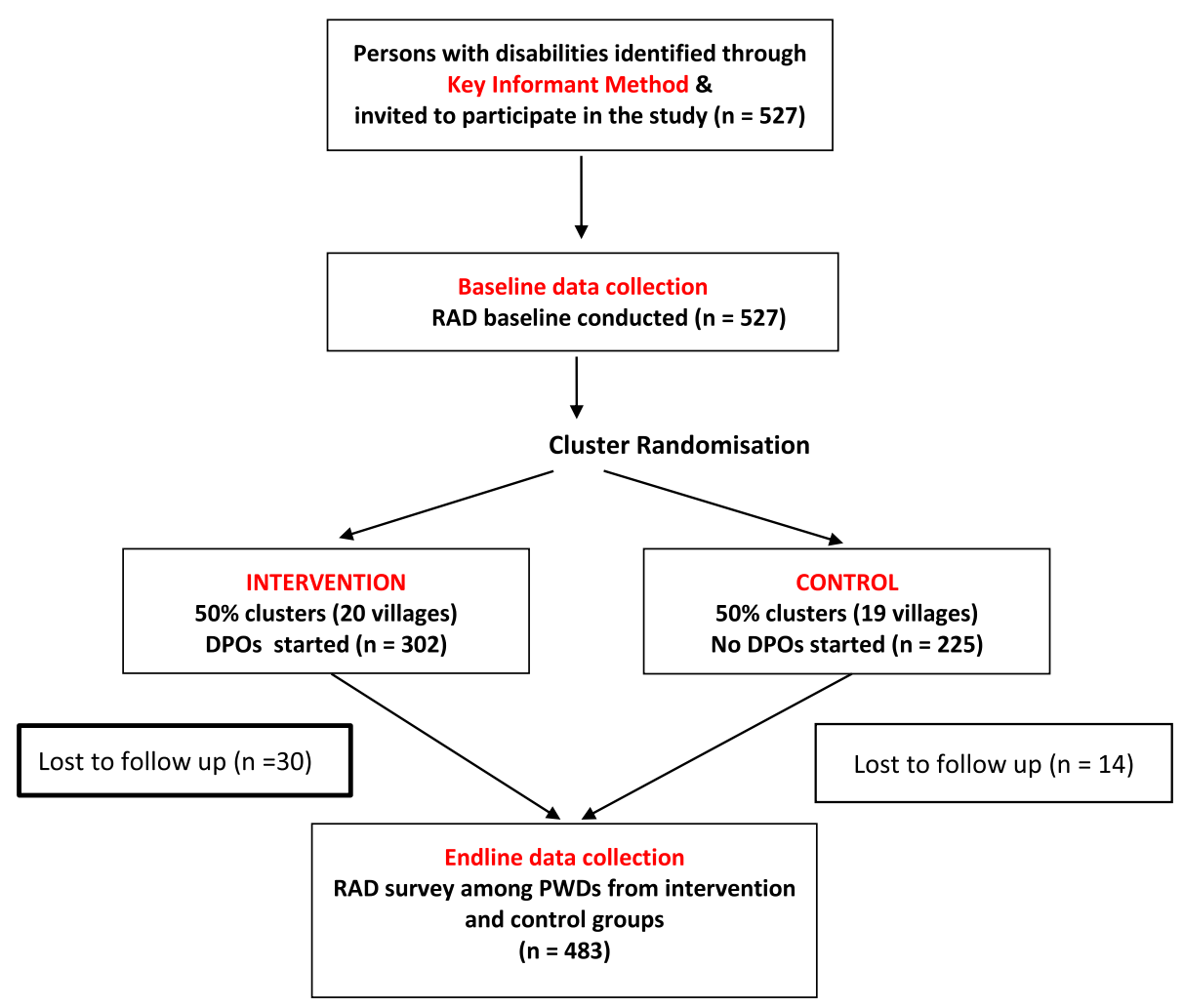

Fig. 1 Flow chart of steps in the cluster randomized intervention study

in percentages of met needs were more substantial across all participation variables in the intervention group, except access to toilet facilities of which the increases were approximately the same in the two groups. In almost all the access to services/facilities items in the control group, the $95 \%$ confidence intervals of proportions of the two time points overlapped. This indicates that there was not enough evidence of a difference in proportions between baseline and endline.

When we applied the Generalised Estimated Equations, accounting for the cluster effect and the effect of the implementing agencies, nearly all the variables showed evidence of improvement in participation (Table 6). That

Table 1 Reasons for loss to follow up from baseline to endline

\begin{tabular}{ll}
\hline Reasons for loss to follow up & No. \\
\hline Mismatched B/L to E/L & 12 \\
Technical error & 3 \\
Died & 15 \\
Married \& moved away & 2 \\
Did not Consent & 6 \\
Relocated & 2 \\
Could not find & 4 \\
Total & 44 \\
\hline
\end{tabular}

is, after controlling for implementing agencies, the odds of met needs for these variables in the intervention group were at least 2.6 of those not in the intervention program.

Out of the 6 access variables, only access to work and access to safe drinking water showed little evidence of a difference between intervention and control groups. Access to legal aid could not be tested using the GEE due to extremely small numbers.

Table 2 Demographics of participants in intervention and control groups

\begin{tabular}{|c|c|c|}
\hline & Intervention $(n=272)$ & Control $(n=211)$ \\
\hline Age (Mean, SD) & $40.5(14.8)$ & $43.4(15)$ \\
\hline Female (n, \%) & $107(39.3 \%)$ & $71(33.7 \%)$ \\
\hline Married (n, \%) & $150(55.2 \%)$ & $130(61.6 \%)$ \\
\hline Ever attended school $(n, \%)$ & $166(61 \%)$ & $124(58.8 \%)$ \\
\hline \multicolumn{3}{|l|}{ Socio Economic Status ${ }^{\mathrm{ab}}$} \\
\hline Lowest 40\% & $100(37.6 \%)$ & $89(43.4 \%)$ \\
\hline Middle 40\% & $120(45.1 \%)$ & $68(33.2 \%)$ \\
\hline Highest 20\% & $46(17.3 \%)$ & 48 23.4\%) \\
\hline
\end{tabular}

${ }^{\mathrm{a} S o c i o-e c o n o m i c}$ status was based on total composite SES scores derived from household variables (land ownership, type of brick walls, floors, fuel, assets, electricity, stock and microcredit)

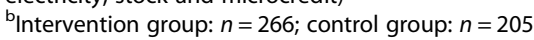


Table 3 Changes in Well-being indicators in the control and intervention groups

\begin{tabular}{|c|c|c|c|c|}
\hline \multirow[t]{2}{*}{ Well-being } & \multicolumn{2}{|c|}{$\%$ of met needs at baseline $(n ; 95 \% \mathrm{Cl})$} & \multicolumn{2}{|c|}{$\%$ of met need at endline $(n ; 95 \% C l)$} \\
\hline & Intervention & Control & Intervention & Control \\
\hline Confident & $46 \%(99,35.7$ to $56.7 \%)$ & $48.5 \%(72,33.5$ to $63.8 \%)$ & $59.9 \%(130,46.6$ to $71.8 \%)$ & $45.1 \%(77,21.8$ to $70.7 \%)$ \\
\hline Respected by community & $81.4 \%(191,66.2$ to $90.7 \%)$ & $75.3 \%(124,64.6$ to $83.5 \%)$ & $84.3 \%(211,73.5$ to $91.2 \%)$ & $82.8 \%(153,69.1$ to $91.1 \%)$ \\
\hline Opinion & $67 \%(154,60$ to $73.4 \%)$ & $63.1 \%(104,55.9$ to $69.7 \%)$ & $75.6 \%(179,66.4$ to $82.9 \%)$ & $62.1 \%(117,52.5$ to $70.9 \%)$ \\
\hline Able to make friends & $23.9 \%(55,11.4$ to $43.5 \%)$ & $18.2 \%(37,8$ to $36.3 \%)$ & $37.8 \%(89,20.3$ to $59.1 \%)$ & $32.4 \%(55,15.7$ to $55.4 \%)$ \\
\hline Living condition & $75.6 \%(181,54.2$ to $89 \%)$ & $69 \%(130,49.3$ to $83.6 \%)$ & $91.1 \%(237,81.4$ to $96 \%)$ & $82.3 \%(163,68.2$ to $91 \%)$ \\
\hline Help Others & $20.1 \%(41,7.4$ to $44.1 \%)$ & $11.1 \%(25,5.5$ to $21.4 \%)$ & $34.3 \%(76,16.4$ to $58.2 \%)$ & $32.4 \%(52,10.9$ to $65.2 \%)$ \\
\hline
\end{tabular}

apercentages were weighted by sampling weights i.e. total sample / number of sample in the cluster

\section{Discussion}

This is the first randomised control trial in any LMIC to quantitatively demonstrate the impact of DPOs - a key element of the disability response. The study shows how an intervention to facilitate DPOs may lead to significant improvement in many areas of well-being and access to services and facilities. DPOs were demonstrated to be associated with substantial improvement in access to most of the services and facilities, whereas sense of well-being was improved in two of the six variables. This study has significant implications for the practice of disability inclusive development in terms of advocating for the role of DPOs and generating further support for them. These results likely underestimate the DPO's effect for those individuals who are participating in the DPO because this study measured the DPO's impact on all people with disabilities in the community; not just those who participated in the DPO, although the odds ratio of 15 for access to DPO seems to indicate that many of the study participants were accessing the DPO.

Research has shown that people with disabilities are more likely to have smaller and less diverse social networks compared to people without disabilities [24-26]. Almost by definition the social network for people with disabilities was expanded through the intervention which involved the formation of a DPO. Indeed the parallel qualitative studies [14] (published elsewhere) indicated that participation in the DPO, as expected, has increased the social networks of people with disabilities. Social Network Analysis is currently being undertaken to map out the social networks of the DPO participants, before and after the DPO formation. Growing the social network is important as the literature indicates that social networks, in themselves, are important indicators for an individual's health and well-being [27, 28]. Intuitively increased access to rehabilitation services, toilet facilities and social welfare program might expect to lead to improved health outcomes for those with disabilities. Although change in health status was not measured, the multidimensional well-being and improvements were observed in some domains.

The overall budget of the DPO intervention was around USD $\$ 18,000$ per year across 25 villages. This small investment has resulted in a widespread gain across access, participation and well-being for people with disabilities. Therefore, this intervention, and the formation and support of DPOs, seemingly represents a highly cost-effective investment.

However, improvement was not seen in all domains. Some national programs and insurance programs in disability, such as the National Disability Insurance Scheme (NDIS) in Australia, are predicated on the relationship between increased access to services/care resulting in increased employment of people with disabilities and, in turn, increased Gross Domestic Product (GDP). However, in this study, despite increased access to services

Table 4 Association between intervention and well-being

\begin{tabular}{|c|c|c|c|c|c|}
\hline \multirow[t]{2}{*}{ WELL-BEING } & \multirow[t]{2}{*}{$n$} & \multicolumn{2}{|l|}{ Model $1^{\text {a }}$} & \multicolumn{2}{|l|}{ Model $2^{b}$} \\
\hline & & Intervention Odds Ratio (95\% Cl) & $p$-value & Intervention Odds Ratio (95\% Cl) & $p$-value \\
\hline Confident & 370 & $1.12(0.5$ to 2.6$)$ & 0.78 & 1.64 (0.9 to 2.98$)$ & 0.15 \\
\hline Respected by community & 402 & 1.36 (0.58 to 3.22$)$ & 0.48 & 1.34 (0.6 to 3.0$)$ & 0.47 \\
\hline Opinion & 399 & $1.62(0.85$ to 3.1$)$ & 0.14 & 1.94 (1.16 to 3.24$)$ & 0.01 \\
\hline Able to make friends & 341 & $1.3(0.45$ to 3.79$)$ & 0.63 & 1.63 (1 to 2.65$)$ & 0.05 \\
\hline Living condition & 433 & $2.28(0.96$ to 5.41$)$ & 0.06 & 2.01 (0.89 to 4.62$)$ & 0.09 \\
\hline Help Others & 380 & $0.83(0.24$ to 2.86$)$ & 0.76 & 1.28 (0.7 to 2.33$)$ & 0.42 \\
\hline
\end{tabular}

${ }^{a}$ Explanatory factors: group and baseline; adjusted for clusters (ADPs)

bexplanatory factors: group, baseline and NGO; adjusted for clusters (ADPs) Chamba (NGO) was the reference group in the GEE model 2 with implementing NGO added as a covariate 
Table 5 Changes in Access to services and facilities, and Community Participation in control and intervention groups

\begin{tabular}{|c|c|c|c|c|}
\hline \multirow[t]{2}{*}{ Access and Participation } & \multicolumn{2}{|l|}{$\begin{array}{l}\% \text { of met needs at baseline }{ }^{a} \\
(n, 95 \% \text { Cl) }\end{array}$} & \multicolumn{2}{|l|}{$\begin{array}{l}\% \text { of met need at endline } \\
(n, 95 \% \mathrm{Cl})\end{array}$} \\
\hline & Intervention & Control & Intervention & Control \\
\hline Work & $63.3 \%(119,52.5$ to $73 \%)$ & $75.4 \%(116,55.1$ to $88.4 \%)$ & $81.5 \%(166,72.2$ to $88.2 \%)$ & $74.9 \%(128,54.4$ to $88.2 \%)$ \\
\hline Community Consultation & $58.9 \%(99,39.4$ to $75.9 \%)$ & $65 \%(78,38.1$ to $84.9 \%)$ & $67.3 \%(124,51.4$ to $80 \%)$ & $58.8 \%(76,26.7$ to $84.8 \%)$ \\
\hline Rehabilitation services & $19 \%(27,12.3$ to $28.3 \%)$ & $43.2 \%(40,33.8$ to $53.1 \%)$ & $70 \%(45,47.8$ to $85.6 \%)$ & $30 \%(17,20$ to $42.4 \%)$ \\
\hline Access to safe drinking water & $86.6 \%(210,77.4$ to $92.4 \%)$ & $88.7 \%(159,72.6$ to $95.9 \%)$ & $90.8 \%(240,85.1$ to $94.5 \%)$ & $87.5 \%(179,80$ to $92.5 \%)$ \\
\hline Access to toilet facilities & $92.4 \%(234,87.5$ to $95.4 \%)$ & $95.2 \%(183,82.3$ to $98.8 \%)$ & $96.9 \%(263,94.3$ to $98.4 \%)$ & $93.6 \%(201,90.2$ to $95.9 \%)$ \\
\hline Able to participate in social activities & $70.8 \%(147,55.3$ to $82.5 \%)$ & $85.3 \%(117,69.2$ to $93.8 \%)$ & $81.6 \%(185,66.2$ to $91 \%)$ & $77.7 \%(125,54.7$ to $90.9 \%)$ \\
\hline Access to Govt. social welfare services & $69.8 \%(129,60.8$ to $77.5 \%)$ & $80.1 \%(106,69.2$ to $87.8 \%)$ & $89.4 \%(201,78.6$ to $95.1 \%)$ & $79.1 \%(126,57.2$ to $91.4 \%)$ \\
\hline Access to DPO & $15.4 \%(14,6$ to $34.2 \%)$ & $24.4 \%(12,19.7$ to $29.8 \%)$ & $56.7 \%(125,40.1$ to $71.9 \%)$ & $22.4 \%(11,5.2$ to $60.3 \%)$ \\
\hline Access to legal Aid & $70.5 \%(21,44$ to $87.9 \%)$ & $90.3 \%(34,61.5$ to $98.2 \%)$ & $87.3 \%(34,56.3$ to $97.3 \%)$ & $77.5 \%(24,26.9$ to $97 \%)$ \\
\hline
\end{tabular}

apercentages were weighted by sampling weights i.e. total sample / number of sample in the cluster

and rehabilitation, employment was the access variable that did not show any improvement. Nonetheless, access to work is a more distal outcome, which over time, might be expected to increase due to increased wellbeing and access to services. Additionally, the way that the question was asked "do you have as much access to work as you would like" may have not captured increase work in the informal sector. For example, even if the intervention increased engagement in domestic and subsistence work (not salaried), this would probably not have been reported as "access to work".

The loss to follow up was acceptable $(8 \%)$ and the most common factor for failure to follow up was the death of the participants $(n=15)$. In a study population of 527 people this death rate (14.2 deaths per 1000 population per year) is dramatically higher than expected for adult males in India for whom the crude mortality rate is 7.3 deaths per 1000 population/year [29] Higher death rates among people with disabilities are observed worldwide, and more markedly in LMICs. Decreasing mortality was not an outcome measure in this study but, given enough time, one would anticipate that the increase in access and well-being might translate to decreasing this high mortality rate.

The context of the DPO formation seems to be important as indicated by the implementing partner, or NGO, being a confounder which when controlled for changed the findings. Therefore, the way that a DPO is facilitated and supported seems to be important for its success and this finding was supported from the parallel qualitative study undertaken by Young et al. [14]. This raises the contention as to how much external support and facilitation is helpful or necessary for DPOs. From a disability rights perspective, DPO should be conceived of, planned, initiated, led and operated exclusively by people with disabilities. Yet in this study the level and quality of external supports seems to be important for the establishment and effectiveness of the DPO.

Acknowledging that the context is important, the qualitative study [30] and realist review [14] conducted

Table 6 Association between intervention and access/participation outcomes

\begin{tabular}{|c|c|c|c|c|c|}
\hline \multirow[t]{2}{*}{ Access and participation } & \multirow[t]{2}{*}{$n$} & \multicolumn{2}{|l|}{ Model $1^{a}$} & \multicolumn{2}{|l|}{ Model $2^{b}$} \\
\hline & & Intervention Odds Ratio $(95 \% \mathrm{Cl})$ & $p$-value & Intervention Odds Ratio (95\% Cl) & $p$-value \\
\hline$\overline{\text { Work }}$ & 295 & $0.66(0.26$ to 1.69$)$ & 0.39 & $0.76(0.32$ to 1.79$)$ & 0.53 \\
\hline Community Consultation & 255 & 1.83 (0.68 to 4.93$)$ & 0.23 & 2.57 (1.40 to 4.72$)$ & 0.002 \\
\hline Rehabilitation services & 71 & 6.69 (2.42 to 18.48$)$ & 0.00 & $6.83(2.4$ to 19.42$)$ & $<0.001$ \\
\hline Access to safe drinking water & 444 & 1.45 (0.71 to 2.94$)$ & 0.30 & 1.53 (0.84 to 2.78$)$ & 0.16 \\
\hline Access to toilet facilities & 400 & 2.75 (0.81 to 9.37$)$ & 0.02 & $3.89(1.31$ to 11.57$)$ & 0.01 \\
\hline Able to participate in social activities & 327 & 2.46 (0.99 to 6.11$)$ & 0.05 & 2.46 (1.38 to 4.38$)$ & 0.002 \\
\hline Access to Govt. social welfare services & 295 & 3.53 (1.29 to 9.69$)$ & 0.01 & $4.82(2.35$ to 9.91$)$ & $<0.001$ \\
\hline Access to DPO & 69 & 12.24 (1.54 to 97.29$)$ & 0.02 & 14.78 (1.43 to 152.43$)$ & 0.01 \\
\hline Access to legal Aid & 17 & 1.13 (0.86 to 1.5$)$ & 0.38 & NA & NA \\
\hline
\end{tabular}

${ }^{\mathrm{a}}$ Explanatory factors: group and baseline; adjusted for clusters (ADPs)

bexplanatory factors: group, baseline and NGO; adjusted for clusters (ADPs) Chamba (NGO) was the reference group in the GEE model 2 with implementing NGO added as a covariate 
in parallel to this quantitative study are important for understanding the specific context for the changes. This provides useful learnings as to how and why the DPO worked in this setting. This contextual information from the qualitative work may help the reader determine if and/or how to undertake this intervention in other contexts.

\section{Limitations}

The generalizability of these findings is limited given this study was in only two districts. The study was perhaps statistically underpowered to detect changes in the wellbeing domains. All well-being indicators improved in the intervention group more than in the control group arm yet only two of six well-being variables showed enough evidence of a difference. This seemingly relates to the sample size indicated by a wide $95 \%$ confidence interval of odds ratio for 'living conditions' (0.89 to 4.62, $p=$ 0.09 ) and 'confidence' ( 0.9 to $2.98, p=0.15$ ).

The ratio of males $(n=305)$ to females $(n=178)$ is seemingly skewed. However, this is partly explained by a higher prevalence of disability in males $(8.1 \%)$ than in females (6.7\%) in these districts in Uttarakhand [18]. If we apply these prevalence estimates to our study sample, then we would expect 264 males and 219 females. While this may indicate an under-representation of women with disabilities in our sample, this also may reflect the reality of entrenched inequalities facing women with disabilities: in India, women are often given less value in a society. It is possible that women with disabilities were less visible or excluded, making it more challenging for our informants to identify women with disabilities [19]. To address this in the future research, it may be beneficial to enlist support from local women's network to effectively encourage women with disabilities to part-take in surveys and to ensure studies are carried out in the most considerate, sensitive way.

\section{Conclusion}

This study is the first to provide quantitative evidence that DPOs are in fact effective at increasing participation, access and well-being. DPOs are the mainstay of disability responses worldwide and a key element for the disability rights movement [7]. This study supports the ongoing role of DPOs and suggests that investing in supporting their establishment, facilitation and strengthening is a cost-effective intervention. Government programs should continue to work closely with the NGOs and community-based organisations to strengthen DPOs. This could include undertaking training, building technical capacity building in running a society, lining them with appropriate NGOs. A future study is planned to assess the sustainability of the effects demonstrated.

\section{Abbreviations}

DFAT: Department of Foreign Affairs and Trade; DID: Disability inclusive development; DPO: Disabled People's Organisation; GDP: Gross Domestic Product; ICF: International classification of Functioning, Disability and Health; KI: Key Informant; LMIC: Low-and Middle-Income Country; NDIS: National Disability Insurance Scheme; NGO: Non-Governmental Organisation; RAD: Rapid Assessment of Disability; SES: Socio-Economic Status; SHG: SelfHelp Group; UNCRPD: The United Nations Convention on the Rights of Persons with Disabilities

\section{Acknowledgements \\ The authors would like to thank CBM for the funding support, their responsiveness and helpful engagement throughout the duration of the entire RAD project. With CBM's sponsorship, the Public Health Foundation of India and the Nossal Institute for Global health of the University of Melbourne became partners in conducting this research. We acknowledge the support of field research teams under the CHGN Uttarakhand Cluster for their support in data collection. The teams were AKS HOPE, OPEN, Chamba Christian hospital and EHA (Samvedna and Anugrah projects).}

\section{Authors' contributions}

Contributors NJG, GVSM. LS and FS conceived of the study and the overall design, $\mathrm{MH}$ and CPW performed data analysis, and KA and NJG wrote the first draft and NJG wrote the subsequent drafts. CPW led the response to the reviewer's comments and provided subsequent analysis. LS supported the acquisition, analysis and interpretation of the data. NJG and FS supported study design, analysis and overview of the whole paper. All the above authors provided input into drafts of the paper, and read and approved the manuscript.

\section{Funding}

The funding body was CBM India Trust. They were not involved in the study design, data collection or implementation. The small amount of funding did limit the eligible clusters for inclusion. They do not use grant numbers.

\section{Availability of data and materials}

The datasets used and/or analysed during the current study are available from the corresponding author on reasonable request.

\section{Ethics approval and consent to participate}

Ethics approval was obtained through the Indian Institute of Public Health (Hyderabad) Ethics committee and the Community Health Global Network (CHGN) Uttarakhand Cluster Ethics committee. Fully informed written consent to participate was obtained from each individual.

Consent for publication

Not applicable.

\section{Competing interests}

The authors declare that they have no competing interests.

\section{Author details}

${ }^{1}$ Nossal Institute for Global Health and Australia-India Institute, University of Melbourne, Level 5, 333 Exhibition Street, Melbourne 3000, Australia. ${ }^{2}$ Australia India Institute, University of Melbourne, 147-149 Barry Street, Carlton, VIC 3053, Australia. ${ }^{3}$ Murdoch Children's Research Institute, 50 Flemington Rd, Parkville 3052, Australia. ${ }^{4}$ Nossal Institute for Global Health, University of Melbourne, Level 5, 333 Exhibition Street, Melbourne 3000, Australia. ${ }^{5}$ Indian Institute of Public Health-Hyderabad, Plot \# 1, A.N.V.Arcade, Amar Co-op Society, Kavuri Hills, Madhapur, Hyderabad 500 033, India. 'Pari Mahal' D-55 Aman Vihar, Lane no.10, Chidowali, P.O:Kandoli, Sahastradhara Road, Dehra dun, Uttarakhand, India. ${ }^{7}$ CBM, \#140, "Commerce Cube", 5th Main, Puttannachetty Road, Chamarajpet, Bengaluru, Karnataka 560018 , India. 
Received: 9 October 2018 Accepted: 10 January 2020

Published online: 31 January 2020

\section{References}

1. World Health Organization and the World Bank. World Report on Disability 2011 [Available from: http://www.who.int/disabilities/world_report/2011/en/.

2. World Health Organization. Disabilities Geneva: WHO; 2018 [Available from: http://www.who.int/topics/disabilities/en/

3. World Health Organization. Health statistics and information system Geneva WHO; 2016 [Available from: http://www.who.int/healthinfo/global_burden_ disease/en/.

4. Government of India. Disability in India - A statistical profile. Ministry of Statistics. 2011.

5. World Bank. People with disabilities in India: from commitments to outcomes 2009 [Available from: http://documents.worldbank.org/curated/ en/577801468259486686/pdf/502090WPOPeopl1Box0342042B01PUBLIC1.pdf.

6. United Nations. Disability inclusive development. Toolkit on Disability for Africa. : Division for social policy development, Department of Economic and social affairs. ; [Available from: http://www.un.org/esa/socdev/ documents/disability/Toolkit/Disability-inclusive-development.pdf.

7. UN General Assembly. Convention on the Rights of Persons with Disabilities New York: UN; 2007 [Available from: https://www.un.org/development/ desa/disabilities/convention-on-the-rights-of-persons-with-disabilities.html].

8. Young R, Reeve M, Grills N. The functions of Disabled People's Organisations (DPOs) in low and middle-income countries: a literature review. Disabil CBR Inclusive Dev. 2016;27(3):45-71.

9. Commonwealth of Australia D. Development for All 2015-2020: Strategy for strengthening disability-inclusive development in Australia's aid program. 2015.

10. Marella M, Busija L, Islam A, Devine A, Fotis K, Baker S, et al. Field-testing of the rapid assessment of disability questionnaire. BMC. 2014;14(900). https:// doi.org/10.1186/1471-2458-14-900.

11. Bonfils I. Disability meta-organizations and policy-making under new forms of governance. Scand J Disabil Res. 2011;13(1):37-51.

12. Griffiths M, Mannan H. Empowerment, advocacy and national development policy:a case study of DPOs in Bolivia. Disabil Int Dev. 2009:105-17.

13. Cornielje $\mathrm{H}$. The role and position of disabled people's organisations in community based rehabilitation. Asia Pacific Disabil Rehab. 2009;20(1):3-14.

14. Young R, Reeve M, Devine A, Singh L, Grills N. A realist evaluation of the formation of groups of people with disabilities in North India. Christ J Glob Health. 2016;3(2):72-90.

15. Kumaran K. Role of self-help groups in promoting inclusion and rights of persons with disabilities. Disabil CBR Inclusive Dev. 2011;22(2):105-13.

16. Australia, People with Disability. 2018 [Available from: https://pwd.org.au/ resources/disability-info/student-section/disabled-people-s-organisations-dpos].

17. Huq NL, Edmonds TJ, Baker SM, Busjia L, Devine A, Fotis K. The rapid assessment of disability - informing the development of an instrument to measure the effectiveness of disability inclusive development through a qualitative study in Bangladesh. Disabil CBR Inclusive Dev. 2013;24(3):37-60.

18. Grills N, Singh L, Pant H, Varghese J, Murthy GVS, Hoq M, et al. Access to services and barriers faced by people with disabilities: a quantitative survey. DCIDJ. 2017;28(2):23-24.

19. Muhit S, Shah S, Gilbert C, Hartley S, Foster A. The key informant method: a novel means of ascertaining blind children. Br J Ophthalmol. 2007;91:995-99.

20. The Washington Group on Disability 2016 [Available from http://www washingtongroup-disability.com/washington-group-question-sets/short-setof-disability-questions/].

21. Hawtin K, Grills NJ. The rapid assessment of disability (RAD) survey in India: a process evaluation Melbourne University: the Nossal institute; 2015.

22. Marella M, Devine A, Armecin GF, Zayas J, Marco MJ, Vaughan C. Rapid assessment of disability in the Philippines: understanding prevalence, wellbeing, and access to the community for people with disabilities to inform the W-DARE project. Popul Health Metrics. 2016;14(1):26.

23. Ramachandra SS, Allagh KP, Kumar H, Grills N, Marella M, Pant H, et al. Prevalence of disability among adults using rapid assessment of disability tool in a rural district of South India. Disabil Health J. 2016;9(4):624-31.

24. Mithen J, Aitken Z, Ziersch A, Kavanagh AM. Inequalities in social capital and health between people with and without disabilities. Soc Sci Med. 2015;126: 26-35.

25. Miles S, Fefoame GO, Mulligan D, Haque Z. Education for diversity: the role of networking in resisting disabled People's marginalisation in Bangladesh. Compare. 2012;42(2):283-302.
26. Eisenman LT, Farley-Ripple E, Culnane M, Freedman B. Rethinking social network assessment for students with intellectual disabilities (ID) in postsecondary education. J Postsecondary Educ Disabil. 2013;26(4):367-84.

27. Perkins JM, Subramanian SV, NA. C. Social networks and health: a systematic review of sociocentric network studies in low- and middle-income countries. Soc Sci Med. 2015;125:60-78.

28. Bergland A, Meaas I, Debesay J, Brovold T, Jacobsen EL, Antypas K. Associations of social networks with quality of life, health and physical functioning. Eur J Phys. 2016;18(2):78-88.

29. Knoema 2018. India Crude Mortality Rate. Available from: https://knoema. com/atlas/India/topics/Demographics/Mortality/Crude-death-rate.

30. Leung M, Devine A, Singh L, Yip T-W, Grills N. With Hope to Help Ourselves and Others': The Impact of Disabled People's Organisations on the Lives of Persons with Disability in Uttarakhand, North India. Rev Disabil Stud. 2019;15(2): 33-44.

\section{Publisher's Note}

Springer Nature remains neutral with regard to jurisdictional claims in published maps and institutional affiliations.
Ready to submit your research? Choose BMC and benefit from:

- fast, convenient online submission

- thorough peer review by experienced researchers in your field

- rapid publication on acceptance

- support for research data, including large and complex data types

- gold Open Access which fosters wider collaboration and increased citations

- maximum visibility for your research: over $100 \mathrm{M}$ website views per year

At BMC, research is always in progress.

Learn more biomedcentral.com/submissions 